\title{
Responsabilidade social corporativa e marketing social: um estudo exploratório em empresas para o fortalecimento do turismo na região da baixada santista (São Paulo/BR)
}

\author{
Hamilton Pozo ${ }^{i}$ \\ Takeshy Tachizawa ii
}

Faculdade Campo Limpo Paulista (Brasil)

\begin{abstract}
Resumo: Este artigo propõe um modelo de gestão para organizações empresariais em termos de responsabilidade social. Esta proposta está alicerçada em resultados de pesquisa empírica, desenvolvida pelo método da grounded theory. O modelo proposto, além de refletir o estágio de responsabilidade social em que se encontra a empresa analisada, subsidia o mapeamento socioambiental dos diferentes segmentos econômicos do universo empresarial brasileiro. O marketing social com base na responsabilidade social já começa a se constituir em diferencial competitivo para as empresas. O objetivo da pesquisa foi apresentar crenças e valores que colaborem com o maior envolvimento e atuação das empresas nesse campo, principalmente no sentido de fortalecer o turismo na Região da Baixada Santista-SP.
\end{abstract}

Palavras-chave: Marketing social; Responsabilidade social; Turismo; Baixada Santista.

Title: Corporate social responsibility and social marketing: an exploratory study into companies to strengthen tourism in the region of lowered from Santos (Sao Paulo / BR)

\begin{abstract}
The social responsibility that, a lot of times, it is confused with philanthropy, becomes to have larger importance for the companies. With the growth of the Third Sector, in financial resources, social and political relevance, and the consequent professionalization of the modern techniques of management are being incorporate to the social area. The social marketing with base in the social responsibility already begins to build a value differential for the brand and a competitive advantage for the companies. The objective of this research was to present values to collaborate with the largest involvement and performance for the companies in that field, mainly in order to strengthen the tourism in the Region of Baixada Santista-SP.
\end{abstract}

Keywords: Social marketing; Social responsibility; Tourism; Baixada Santista.

\footnotetext{
i Departamento de Mestrado em Administração, Faculdade Campo Limpo Paulista - FACCAMP (São Paulo/BR). E-mail: hprbrazil@ hotmail.com.

ii Departamento de Mestrado em Administração, Faculdade Campo Limpo Paulista - FACCAMP (São Paulo/BR). E-mail:usptakes@ uol.com.br.
} 


\section{Introdução}

O presente trabalho se originou da constatação de que as organizações no novo contexto empresarial necessitam compartilhar do entendimento de que deve existir um objetivo comum, e não um conflito, entre desenvolvimento econômico e responsabilidade social, tanto para o momento presente como para as gerações futuras. Induzir as forças de mercado para sua inserção no cenário socioambiental e no uso criterioso de instrumentos econômicos, num contexto harmonioso de regulamentação, é um dos maiores desafios que o mundo empresarial enfrenta na atualidade. Este contexto visa ampliar e proporcionar a abertura de discussões, reflexões e futuras continuações de estudos sobre a aplicação do marketing social e responsabilidade social, em toda sua essência, no mercado global atual. Visa apresentar um panorama dessas especificidades do marketing social e responsabilidade social, numa tentativa de tipificar e distinguir entre as ações decorrentes de sua aplicação e sua convergência e orientação ao mercado.

Com a crescente conscientização do mercado e as campanhas de mudança social de sucesso lançadas tanto pelo governo como por algumas organizações privadas que obtiveram como resultado o bem estar social e o bem estar que se pode definir como lucro social, é uma nova realidade para as organizações. A questão do social e ética nos negócios por muito tempo foi considerada de menor importância. Justifica-se que dentro do enfoque e do mundo dos negócios, nem sempre é possível tomar decisões com a clareza sobre as ações de viés social.

Segundo Scour (1998), os países e empresas capitalistas navegam com desenvoltura na ambigüidade moral já que o interesse pessoal é visto como o motor da economia. Scour resgata as idéias de Weber quando discute Ética falando sobre as duas abordagens: a da convicção e a da responsabilidade. A ética da convicção é interpretada como aquela que está escorada em princípios e fundamenta-se pelas normas morais e ideais. Com o discernimento entre as abordagens da ética da convicção e da responsabilidade, não é difícil compreender porque as organizações da economia de mercado orientam-se pela ética da responsabilidade, justificando sua ação e os meios de que se utilizam para as finalidades do lucro.

Atualmente, pela discussão sobre a ética e o comportamento considerado socialmente responsável, vemos que as organizações estão percebendo que a sociedade civil, de forma cada vez mais claramente, vem associando à qualidade dos bens e serviços produzidos muitos outros valores intangíveis ao produto ou serviço.

Conforme observa Wheatley (1992:34), as questões da ética e da moral já não constituem conceitos religiosos obscuros, mas elementos essenciais nas relações com os componentes da organização, com os fornecedores e com as pessoas envolvidas, ou seja, os stakeholders. Com essa nova dimensão, a empresa pode obter um diferencial de sucesso que traz a desejada vantagem competitiva e - junto com a ética - pode tornar as organizações mais confiáveis e mais justas para com os trabalhadores, a sociedade e a natureza.

Dados mais recentes sobre o mercado brasileiro mostram informações de que há uma tendência de crescimento no setor social, e isso reflete no marketing e na responsabilidade social e no uso correto das suas ferramentas. Esta é uma mudança de paradigma que uma organização deve realizar se realmente está buscando, dentro dos seus valores, cultura, missão e visão, a responsabilidade social corporativa.

Para Kotler (2008), o marketing social é uma estratégia de mudança do comportamento dentro das organizações. A sua combinação com elementos das abordagens tradicionais da mudança social dentro de um processo integrado entre planejamento e ação, aproveitando os avanços da tecnologia das comunicações e as técnicas de Marketing.

Ao analisar empresas que operam com modelos de marketing social e com responsabilidade social, cujas ações efetivamente possam produzir vantagem competitiva e um diferencial estratégico para as mesmas utilizando a ética, tornando-as mais confiáveis e mais justas para com a sociedade e o meio ambiente, busca-se:

- analisar a importância da responsabilidade social para a implementação do marketing social nas organizações; - estudar ações, permitindo a realização de reflexões sobre marketing social; - analisar e descrever a responsabilidade social através do tempo até os dias atuais; - analisar a ética empresarial verificando, desde os seus critérios de eticidade, até seus fatores de lucro para as organizações; - apresentar pesquisa qualitativa para avaliar a responsabilidade social e o marketing social nas organizações localizadas na Baixada santista (São Paulo/BR) e sua ação para fortalecer o turismo.

\section{Aporte teórico}

A responsabilidade social corporativa, na trilha dos inúmeros desastres empresariais ocorridos em consagradas organizações ganha importância como instrumento de gestão para evitar riscos de escândalos econômicos e sinistros ecológicos. Existia, até pouco tempo atrás, o conceito de que responsabilidade social corporativa se resumia no que a empresa podia oferecer para a comunidade, através de campanhas e doações comunitárias. Atualmente, este pensamento expandiu e se tornou mais abrangente, incorporando, além deste conceito, outros fatores importantes, como a preservação do meio ambiente, a valorização do colaborador como parte integrante da empresa, bem como a preocupação em criar medidas que assegurem sua qualidade de vida dentro da organização.

Os clientes, neste novo cenário empresarial, têm expectativas de interagir com organizações que sejam éticas, tenham boa imagem institucional no mercado, e que atuem de forma ecologicamente responsável. Neste am- 
biente emerge a responsabilidade social, que enfatiza o compromisso pela sustentabilidade junto aos stakeholders (clientes, fornecedores, consumidores, colaboradores internos, instituições financeiras, ONGs e comunidade em geral), como instrumento gerencial para a otimização econômica da organização.

Problemas como fome, poluição, crimes, corrupção, aética, entre outros, perpassam toda a história da humanidade desde o surgimento dos primeiros agrupamentos urbanos, ainda na Antiguidade. Para Henderson (2001), tal perspectiva tem se acentuado no mundo contemporâneo desde o início no século XIX, como decorrência das mutações ocorridas na escala de valores humanos, delineadas pela Revolução Industrial. Essas mutações, essência da história da humanidade, evoluíram para os tempos atuais como responsabilidade social. Esta, por sua vez, pode ser compreendida como a forma de gestão que se define pela relação ética e transparente da empresa com o público em geral, e pelo estabelecimento de metas empresariais compatíveis com o desenvolvimento sustentável da sociedade, preservando recursos ambientais e culturais, respeitando a diversidade e promovendo a redução das desigualdades sociais (ETHOS, 2007).

O envolvimento empresarial em ações sociais na comunidade começou na forma de ações voluntárias das empresas, como filantropia corporativa, visando solucionar problemas sociais (Bronn; Vrioni, 2000). Na década de 1960 disseminou-se o conceito de que as empresas deviam exercer responsabilidades que iriam além das obrigações legais, em termos de ações de responsabilidade social, coerentes com suas atividades econômicas. Uma forma de contribuir para o bem estar da sociedade como um todo é por meio de campanhas que objetivem uma mudança cognitiva nas pessoas, de forma que estas abandonem comportamentos ou atitudes prejudiciais ao convívio social. Estas campanhas foram historicamente compreendidas como sinônimo de ações sociais e comunitárias.

Para Carroll (1991) existe uma pirâmide de Responsabilidade Social das Empresas que deve ser aceito dentro dos negócios pelas pessoas de consciência sobre a responsabilidade social. Este fato deve ser enquadrado de tal forma que toda a base do negócio deve ser considerada como fundamental. Sugerindo que quatro tipos de responsabilidades sociais constituem a Responsabilidade Social Corporativa: econômica, legal, ético. e filantrópicas e, podem ser descritas como uma pirâmide.

Os recentes estudos empresariais conduz que o desenvolvimento social das empresas está associado ao conceito de Responsabilidade Social Empresarial, cuja premissa básica consiste na visão de que as empresas e a sociedade estão interligadas e são interdependentes, existindo, assim, um conjunto de expectativas legítimas da sociedade em relação à atuação das empresas e aos resultados que elas alcançam (Wood, 1991). Mais tarde, Wood (1991) acrescentaria a esta proposta outra componente de resultados e de impactos sociais da atuação organizacional, traduzida pelos resultados observáveis associados à relação da empresa com a sociedade (Wood, 1991). Em geral, tanto o modelo de Wartick e Cochran (1985) como os desenvolvimentos posteriores de Wood (1991), amplifica e esclarece a proposta original de Carroll, mas não contrariam as suas premissas nem o seu desenho conceptual (Carroll, 1999).

Deste modo o modelo desenvolvido posteriormente por Wood (1991), amplifica e esclarece a proposta original de Carroll, mas não contrariam as suas premissas nem o seu desenho conceptual (Carroll, 1999). Assim, pode afirmarse que a interpretação do desenvolvimento social das empresas com base na três dimensões sugeridas, permanece atuais e tem resistido às diversas releituras dos principais autores. Da mesma forma, a responsabilidade social empresarial pode ser identificada com os princípios que orientam os processos e influenciam a ação, concretizados em quatro compromissos fundamentais que vinculam a empresa à sociedade: econômico, legal, ético e filantrópico.

Contudo, atualmente, Carroll após ter realizado um trabalho com Mark Schwartz, entende que a formatação vertical do seu modelo antigo não capta a inter-relação entre os diferentes níveis e pode passar uma noção de prioridade do nível económico (que está na base da pirâmide) em relação ao legal, e assim sucessivamente, o que está incorreto. Além disso, defende que o nível discricionário é, em si, desnecessário, e não pode ser uma responsabilidade do negócio. De resto, essa dimensão já está incluída nas orientações éticas. Daí que proponha outro modelo, o qual em vez de ser piramidal e possuir quatro componentes, é "circular" e inclui apenas três componentes (económica, legal e ética), que se cruzam entre si, não havendo predomínio de nenhum sobre os outros, mas sim uma sobreposição (Carroll e Schwartz, 2003). Na década de 1990 surgiram argumentos de que ações sociais, quando desempenhadas por corporações, não eram totalmente altruístas. Nesta época emerge o conceito de que filantropia corporativa engloba uma variedade de atividades e, dentre estas, algumas que podem afetar positivamente a lucratividade da corporação. Assim, o pensamento que defendia como única responsabilidade social da corporação a geração de lucro para seus acionistas, foi gradativamente sendo substituído pela convicção de que essa responsabilidade deve ser considerada como um investimento que pode melhorar o desempenho da organização em longo prazo. Deste modo, esta investigação tem como ponto de partida a ideia de que uma empresa para ser socialmente responsável deve atuar para além das suas obrigações legais. Assim sendo, e dado que o atual paradigma se baseia na ideia de que o simples cumprimento da lei não significa Responsabilidade Social (Carroll; Schwartz, 2003) con- 
sideramos que, existindo empresas que apresentem ações legais como sendo socialmente responsáveis, o fazem, ou por confundirem ambos os conceitos (lei e Responsabilidade Social) ou por pretenderem dar uma ênfase social a ações de carisma legal, com objetivos instrumentais.

É comum confundir o discurso da Responsabilidade Social com o da Ética Empresarial. Na verdade, são duas áreas distintas com pontos em comum, pois a Responsabilidade Social da empresa tem um conceito relativo que depende das normas, valores sociais e expectativas de uma dada época e lugar. E, portanto, ela está contida na Ética Empresarial, pois dela necessita como marco ético para sua delimitação (Valor, 2001).

Para fortalecer o objetivo desta pesquisa, decidiuse adotar uma visão que converge para os conceitos de responsabilidade social corporativa e cidadania empresarial, conforme sugerido por Carroll (1999). Uma das maiores críticas sofridas pelos teóricos da área de business and society é a falta de comprovação de que exista uma relação direta entre a atuação socialmente responsável de uma empresa e seu desempenho econômico que proporcionam uma visão de relação positiva ou negativa. Os argumentos a favor de uma relação negativa defendem a ideia de que as empresas socialmente responsáveis estariam em desvantagem competitiva, por incorrerem em maiores custos. Os defensores de uma relação positiva argumentam que atitudes socialmente irresponsáveis culminarão em um aumento de custos, resultando em desvantagem competitiva (Waddock; Graves, 1997).

Por um longo período, desde a Revolução Industrial, as práticas administrativas estavam voltadas quase que exclusivamente para a determinação de métodos de produção. O taylorismo buscava estabelecer uma relação de reciprocidade entre capital e trabalho para aumentar a produtividade e assegurar o fortalecimento do capital. Neste aspecto, o fator humano seria apenas um recurso que deveria ser otimizado. As ações estavam focadas para dentro das organizações, para aspectos empresariais que os administradores pudessem influenciar diretamente (Duarte, 1986).

A idéia da Responsabilidade Social Corporativa já era conhecida desde 1800 nos Estados Unidos em forma de filantropia e doações corporativas, porém o conceito atual foi desenvolvido somente durante a década de $70 \mathrm{com}$ a noção de que as corporações têm responsabilidades além de suas obrigações legais. A Responsabilidade Social Corporativa é analisada por duas linhas de pensamento, o conceito de mercado livre e a abordagem orientada socialmente, que tentam explicá-la (Bronn; Vrioni, 2000). Estes autores citam duas definições de Responsabilidade Social Corporativa: a política e a tática do envolvimento social de uma corporação, mais além de suas obrigações legais e para o beneficio da sociedade de Enderle e Tavis (1998), e a de Angelidis e Ibrahim (1993), como as ações sociais corporativas cujo propósito é satisfazer as necessidades sociais.

Atualmente, volta-se aos aspectos da filantropia e da boa gestão dos recursos integrando-se ao discurso da Ética Empresarial, do Marketing Social e do Marketing de Relacionamento, com enfoque no mercado, o novo paradigma da Administração de Empresas (Valor, 2001). Outro enfoque é proporcionado por Llena (2000), que apresenta (Quadro 1) uma evolução das diversas concepções da Responsabilidade Social das empresas numa comparação advinda de diversos autores.

Neste contexto, foi implementado este projeto de pesquisa junto aos moradores locais e turistas para identificar a vocação econômica da região. Uma das principais hipóteses da pesquisa foi confirmar as possibilidades do turismo ecológico e ambiental como alternativa ao desenvolvimento econômico da região. Um dos pressupostos adotados na pesquisa foi que a exploração turística consciente, com a preservação do meio ambiente, voltada à geração de empregos e renda para a comunidade, seria a alternativa imediata para o desenvolvimento econômico e social da Região Metropolitana da Baixada Santista. Este segmento econômico pode-se constituir em um verdadeiro carro-chefe do desenvolvimento econômico, social e cultural da Região (Tachizawa, 2010). A base da pesquisa fundamentou-se no contexto regional tendo como elementos importantes:

- a existência de infra-estrutura para o desenvolvimento do turismo;

- o perfil do turista atual e futuro, bem como o potencial que este possui para geração de renda;

- o inventário dos atrativos naturais, ecológicos, históricos e culturais;

- a visão e opinião dos moradores da região em relação

\begin{tabular}{|c|c|l|c|}
\hline Posição & $\begin{array}{c}\text { Reconhece a existência de } \\
\text { certos direitos de alguns }\end{array}$ & Watson (1972) & Básica \\
intermediária & grupos sociais que tenham & Drucker (1970) & Organizacioais \\
& que satis fazer & & (algumas) \\
\hline & Dentro dos objetivos da & Davis; Blomstron (1966) & Básica \\
\hline Responsabilidade & empresa se inclui os sociais & Garcia (1982) & Organizacioais \\
social plena & como umaparte importante & Carroll; Schwartz (2003) & societárias \\
\hline
\end{tabular}

Quadro 1 - Concepções da Responsabilidade Social da empresa. Fonte. Llena (2000) 
ao turismo na região.

Dado ao enorme potencial da região para o ecoturismo, ainda inexplorado, a pesquisa procurou abranger o conjunto de serviços diferenciados que os municípios têm a oferecer aos turistas. É o potencial turístico da região que pode ser geográfico (existência natural), cultural (provocado pela intervenção do ser humano) e outros aspectos afins (SEADE, 2008). Foi dada ênfase especial àqueles bens e serviços turísticos que possibilitariam o exercício do ecoturismo e atividades auto-sustentáveis, com potencial de criação de empregos e renda à comunidade local. Constatou-se que a grande maioria destes visitantes retornava à sua cidade de origem no mesmo dia. Além disso, a região tem uma grande variedade de atividades que acontecem durante o ano e atraem visitantes, no turismo de curta duração.

O marketing social, para Zenone (2006: 65-67), é uma "extensão de marketing ao longo de sua dimensão substantiva, isto é, a ampliação das áreas concernentes ao marketing para focar os interesses em longo prazo dos consumidores e da sociedade. $\mathrm{O}$ conceito de marketing social sustenta que a organização deve determinar as necessidades, desejos e interesses dos mercados-alvo, e então proporcionar aos clientes um valor superior de forma a manter ou melhorar o bem-estar do cliente e da sociedade. A administração de marketing concentrase em equilibrar três fatores ao definir sua política de mercado: os lucros da empresa, os desejos do consumidor e os interesses da sociedade."

De acordo com o posicionamento de Massó (1998), o Marketing Social Corporativo engloba as atividades que desenvolve uma empresa com o objetivo de obter o compromisso dos consumidores com um determinado comportamento de interesse social favorecendo, ao mesmo

\begin{tabular}{|c|c|}
\hline NIVEL EXTERNO & NIVEL INTERNO \\
\hline Posicionamento diferenciado da marca & $\begin{array}{l}\text { Cumprir com a função social da } \\
\text { empresa }\end{array}$ \\
\hline Tamanho de notoriedade & $\begin{array}{l}\text { Proporcionar valor agregado aos } \\
\text { acionistas }\end{array}$ \\
\hline Captação de novos clientes & $\begin{array}{c}\text { Afiançar a lealdade e o } \\
\text { compromisso dos parceiros }\end{array}$ \\
\hline $\begin{array}{l}\text { Aumento da base de dados de clientes } \\
\text { e de potenciais }\end{array}$ & $\begin{array}{l}\text { Desenvolver estratégias } \\
\text { mercado inovadoras }\end{array}$ \\
\hline Eidelidade do cliente atual & $\begin{array}{l}\text { Melhora na comunicação e no } \\
\text { clima de trabalho }\end{array}$ \\
\hline Melhora da imagem da marca & Fomentar a cultura corporativa \\
\hline Melhora na imagem corporativa & Melhor posicão competitiva \\
\hline Contribuicão à identidade corporativa & $\begin{array}{c}\text { Incrementar a motivação dos } \\
\text { parceiros }\end{array}$ \\
\hline Melhorar a relacão com o mercado & Apresentar balancos positivos \\
\hline $\begin{array}{l}\text { Aumento da influência da empresa na } \\
\text { sociedade }\end{array}$ & Obtenção de incentivos fiscais \\
\hline $\begin{array}{l}\text { Melhora das relações com sindicatos e } \\
\text { associacões }\end{array}$ & $\begin{array}{c}\text { Criação de valores mais } \\
\text { abrangentes }\end{array}$ \\
\hline Melhores contratos publicitários & Maior retorno interno \\
\hline $\begin{array}{l}\text { Acesso forte aos formadores de } \\
\text { opinião }\end{array}$ & $\begin{array}{c}\begin{array}{c}\text { Satisfação e auto estima dos } \\
\text { parceiros }\end{array} \\
\end{array}$ \\
\hline $\begin{array}{l}\text { Apoio ao lançamento de novos } \\
\text { produtos }\end{array}$ & Fortalecimento da marca \\
\hline $\begin{array}{l}\text { Abertura a novos segmentos de } \\
\text { mercado }\end{array}$ & $\begin{array}{l}\text { Desenvolvimento estratégico e } \\
\text { pessoal }\end{array}$ \\
\hline
\end{tabular}

Quadro 2 - Vantagens para as empresas a nível externo e interno. Fonte. Izquierdo (2000),

no quadro 2.

Para Jones apud Aragão (2000, p.46), como conceito, a responsabilidade social refere-se à noção de que as empresas têm obrigações com outros grupos constituídos na sociedade, além dos acionistas. Gonçalves (1980) afirma que a empresa existe para o cumprimento dos objetivos de natureza econômica e também de natureza social; essas funções devem ser desempenhadas de modo integrado. Fica clara a déia de que a otimizacão do lucro não pode perma-

EXTERNO tempo e de forma direta, os interesses da empresa quanto a sua posição no mercado. Já, para García, Gibaja e Mujika (2001), o marketing com táticas promocionais esporádicas para incrementar as vendas no curto prazo deveria ser o estágio inicial do Marketing Social Corporativo, interpretado como uma relação estratégica a longo prazo com alguma causa de interesse social na qual trabalha uma entidade sem fins lucrativos. Dessa forma, a empresa exerceria sua Responsabilidade Social como uma harmonia entre o valor social, a missão e a cultura corporativa, integrando-os com as estratégias globais da empresa.

$\mathrm{Na}$ visão de Izquierdo (2000), o Marketing com causa poderia ser considerado uma alternativa operacional do marketing social, com uma série de vantagens para as empresas, a nível externo e interno, conforme evidenciado 
(2007), as empresas passaram a enfrentar um novo desafio; o setor privado viu-se obrigado a ocupar cada vez mais o espaço do setor público.

Um enfoque muito importante é apresentado por Almeida (2007) que coloca:

A miséria é devastadora sob o enfoque ambiental, inaceitável sob o ângulo ético e social e limitante do ponto de vista do mercado potencial para o setor produtivo; limitando renda, empregos e geração de impostos. A sustentabilidade requer maciça inserção de milhões de pessoas na economia de mercado a cada ano.

Para Grajew apud Gaioto (2001), responsabilidade social envolve o comportamento ético e a qualidade nas relações que a empresa estabelece com todos os seus públicos. É um processo contínuo de aprendizagem que, para se concretizar deve ser incorporado à gestão dos negócios. Já, para Kotler (1986), Marketing é um processo social e gerencial pelo qual indivíduos e grupos obtêm o que necessitam e desejam por meio de criação, oferta e troca de produtos de valor com outros. Muitos teóricos estão propondo novas abordagens para o marketing atual. Richers (2001), por exemplo, aponta alguns fatores para o surgimento de tantas formas de explicar o marketing, principalmente daquelas que nada têm a ver com empreendimentos ou negócios com fins lucrativos. O papel do marketing como fator fundamental é identificar necessidades não satisfeitas dos clientes, de forma a colocar no mercado produtos ou serviços que, ao mesmo tempo, proporcionem satisfação às necessidades dos consumidores que não estão satisfeitas.

Leisinger (2001) defende que o grande desafio do marketing moderno está na capacidade que ele tem de criar novas marcas e suas variantes que são marcas fornecem a base em relação à qual os consumidores podem identificar e associar um produto ou serviço líder e, ainda, de controlar seus destinos.

É preciso reconhecer a necessidade de considerar todos os stakeholders ao projetar e implementar estratégias de Marketing. McCarthy (2000) apresenta sua idéia dizendo que as ferramentas de marketing interagem entre si processando fortes elos entre a organização e o mercado para atender à consecução dos objetivos e à missão organizacional. A imagem da empresa tem papel fundamental na decisão de compra dos consumidores, envolvendo não só a qualidade dos seus produtos e processos, mas também os esforços da empresa em relação às práticas sociais. (Zenone, 2006: 23),

O Marketing social surgiu nos Estados Unidos (1971) e foi usado pela primeira vez por Kotler e Zaltann (1971) que, na época, estudavam aplicação do marketing que contribuísse para a busca e o encaminhamento de soluções para as diversas questões sociais. Conforme Kozel Jr (1997: 214), nesse ano, também, foi publicado, no Journal of Marketing, um artigo de Kotler e Zaltamn (1971):

$O$ marketing social cria e administra todo o processo cujas ações e resultados passam a construir valores que se agregam aos produtos. $O$ assistencialismo, mesmo se efetuado de forma sistemática, pouco agrega ao conceito da empresa, pois ela não gerencia nem detém a autoria e o controle do processo.

Para melhor vislumbrar as idéias de Marketing Social, abaixo são apresentadas algumas afirmações sobre o tema:

a modalidade de ação mercadológica institucional que tem como objetivo principal atenuar ou eliminar os problemas sociais, as carências da sociedade relacionadas principalmente às questões de higiene e saúde pública, de trabalho, educação, habitação, transportes e nutrição. (Vaz, 1995: 280)

Os programas baseados no marketing social são trabalhos cuidadosos de pesquisa, que procuram encontrar a raiz do problema social, identificando-se os focos de resistência a uma mudança (comportamental) e, então, definindo um planejamento de apresentação das idéias, de formulação das propostas e de preparação da estrutura necessária para dar sustentação à campanha. (Vaz, 1995: 281)

O marketing social cria e administra todo o processo, cujas ações e resultados passam a construir valores que se agregam aos produtos. $O$ assistencialismo, mesmo se efetuado de forma sistemática, pouco agrega ao conceito da empresa, pois ela não gerencia nem detém a autoria e o controle do processo. (Kozel Júnior, 1997: 214)

O Marketing social é um dos desenvolvimentos mais promissores, cuja efetiva aplicação espera-se que venha aumentar a eficácia dos agentes sociais de mudança, no sentido de proporcionarem as transformações sociais desejadas. Kotler (2007) coloca que o Marketing social é uma estratégia de mudança de comportamento. Ele combina os melhores elementos das abordagens tradicionais da mudança social em um esquema integrado de planejamento e ação, além de aproveitar os avanços na tecnologia das comunicações e na capacidade do Marketing. Marketing social consiste no emprego do planejamento de mercado, estratégia de análise e técnicas gerenciais tradicionais e inovadoras para garantir o bem-estar do indivíduo e da sociedade.

$\mathrm{O}$ setor da solidariedade tem como objetivo fundamental promover a mudança social, mas isto não é muito simples. As pessoas que vivem em uma determinada sociedade têm seu conceito de vida, sua personalidade e estão implicadas nessa, de acordo com seu vínculo social e no que acontece em sua volta. Dessa forma, dizer que o terceiro setor da solidariedade, as organizações sem fins de lucro e as fundações estão ganhando uma importância muito grande na sociedade, assim, a solução dos problemas sociais implica uma mudança social: mudar as formas com que os indivíduos e os grupos desenvolvem suas vidas, transformando práticas adversas em produtivas, 
modificando as atitudes e os valores nas comunidades e nas sociedades.

A Responsabilidade Social pode chegar a construir, em longo prazo, um valor diferencial para a marca e uma vantagem competitiva para as empresas. Proporcionar mudanças sociais que melhorem a vida é um desafio das campanhas sociais e o objetivo do marketing social presente nas organizações.

A grande diferença entre o marketing social e responsabilidade social é que o marketing social tem como objetivo a mudança de comportamento da sociedade para com o bem-social utilizando ferramentas mercadológicas e técnicas de Marketing, a responsabilidade social é a preocupação que as empresas, pessoas e governo têm pelo social. Portanto, o marketing social deve ser incorporado na estratégia da empresa, no atual ambiente mercadológico, no qual o processo de globalização como mais um desafio a ser vencido pelas corporações, principalmente por meio da busca de produtividade.

Somente poderá ser implementado o Marketing social em uma organização quando existir uma mudança de comportamento internamente aos valores e cultura da empresa com base nos princípios éticos e de responsabilidade social em todo seu processo produtivo, administrativo e comercial para que possa refletir externamente no mercado como imagem da marca por meio do marketing social (Kotler, 2007).

\section{Metodologia da pesquisa}

Os dados da pesquisa empírica desenvolvida ao longo do ano de 2009, e obtidos segundo uma perspectiva indutiva, foram base do presente trabalho. Nesta pesquisa foi utilizado o método grounded theory (Glaser; Strauss, 1967) que é uma modalidade de pesquisa qualitativa que busca gerar novas teorias através de conceitos, categorias e propriedades.

A ênfase da grounded theory é o aprendizado a partir dos dados (interativa e indutiva), e não a partir de uma visão teórica existente (dedutiva). A maior diferença entre grounded theory e outros métodos de pesquisa qualitativa é seu foco específico no desenvolvimento da teoria através de uma contínua interdependência entre a coleta de dados e a análise. É um método que provê uma estrutura metodológica freqüentemente ausente em outras abordagens qualitativas, sem sacrificar a flexibilidade ou o rigor científico.

A grounded theory foi desenvolvida no âmbito da pesquisa em ciências sociais, enfatizando a descoberta indutiva de teorias a partir dos dados analisados sistematicamente. Outros autores desenvolveram e debateram o método (Glaser, Holton, 2004; Strauss, Corbin, 1997) reafirmando que: (a) a proposta principal do método é a construção de teoria, e não somente a codificação e análise de dados; (b) como regra geral, o pesquisador não deve definir um quadro conceitual que antecede ao início da pesquisa, como premissa, para garantir que os conceitos possam emergir sem vieses conceituais pré-definidos; (c) a análise e a conceituação são obtidas através do processo de coleta de dados e comparação constante, no qual cada fatia de dados é comparada com construtos existentes, visando enriquecer uma categoria existente, formar uma nova ou estabelecer novos pontos de relação entre categorias.

Este estudo fundamentou-se, na obtenção de seus propósitos, em dois tipos de pesquisas, uma bibliografia e uma pesquisa primária de natureza qualitativa aplicada a quatro empresas do estado de São Paulo, especificamente localizadas na da Baixada santista (São Paulo).

A pesquisa de campo foi desenvolvida em quatro empresas localizadas na Região da Baixada Santista. Esta pesquisa qualitativa teve como objetivo avaliar e identificar o papel que cada empresa no mercado no qual está inserida, conforme aspectos de responsabilidade social, ação social, marketing institucional, marketing social e filantropia. Ela caracteriza-se por uma pesquisa de mercado descritiva exploratória que, para Mattar (1998), é extremamente variável, segundo as necessidades.

A amostra desta pesquisa é intencional já que não se tem o número certo de empresas nestes estados, e os critérios levantados para obtenção da intencionalidade da amostra foram empresas que utilizam os critérios que envolvem a problemática da pesquisa: Responsabilidade Social, Marketing Social, Ação Social e Filantropia e seu relacionamento com o turismo local. Os levantamentos de dados foram obtidos no período de março a junho de 2009 .

$\mathrm{O}$ instrumento utilizado na coleta de dados foi o de entrevista e, para sua elaboração, foram considerados critérios como a possibilidade de obtenção de dados diretamente do aplicador, privilegiando-se a entrevista com questões abertas, que possibilitem respostas livres com espaços para explicações e comentários. Foram respondidos e considerados corretos 380 questionários que proporcionaram os dados da pesquisa. Como referencial à formulação do questionário, foram consideradas as perguntas que impulsionam esta pesquisa e os objetivos gerais e específicos anteriormente apresentados. A razão fundamental de opção a este método é a complexidade do problema em estudo. Não se trata de medir objetos, mas sim de descobrir a natureza das experiências das pessoas com respeito aos fenômenos condizentes à responsabilidade com que deve ser tratada a vida humana, seus valores, suas decisões. Os questionários foram aplicados diretamente com os colaboradores envolvendo o pessoal de chão de fábrica, de escritório e o pessoal de nível gerencial.

As empresas buscam avanço em seus processos de gestão e, para isso, faz-se necessário que se trabalhe em prol do todo na melhoria dos resultados esperados. Por tudo isso, a abordagem deste trabalho privilegiou, inicialmente, a pesquisa bibliográfica para possibilitar o levantamento do embasamento teórico e da situação atual da gestão da qualidade de vida no trabalho. O levantamento da literatura ocorreu por meio de busca em base de dados físicos e virtuais pertencentes a entidades de ensino superior, centros de pesquisa, órgãos governamentais, órgãos 
de classe, bancos de dados, etc. Deste modo, utilizando-se os descritores obtidos, os dados foram tratados de forma qualitativa em grande parte da pesquisa. Os fatos encontrados foram explicados com base na observação direta e na sua descrição.

$\mathrm{O}$ assunto, em geral, é relacionado ao trabalho e é bem provável que o entrevistado queira garantias de que, ao tomar parte na entrevista, não estará comprometendo a sua empresa. Como, no caso desta pesquisa, todos os entrevistados permitiram a divulgação de seus nomes e, por questão de ética da pesquisa, foi-lhes perguntado se todos os dados coletados na entrevista poderiam ser apresentados neste trabalho e a resposta foi positiva, garantimos a todos que o teor desse trabalho era meramente abordado sob a ótica educacional e que, portanto, não tinha como objetivo denegrir de forma alguma a imagem das organizações em questão. O que funciona em favor do pesquisador é o fato de que as pessoas têm interesse em seus trabalhos e, geralmente, sentem-se lisonjeadas com a oportunidade de expressar seus pontos de vista, independentemente do meio disponível para comunicação. A confiança absoluta precisa ser garantida na abordagem inicial.

$\mathrm{Na}$ pesquisa qualitativa, as amostras geralmente são menores do que nas quantitativas. Entretanto, os dados podem ser mais sutis e complexos. É possível, por exemplo, que a maioria das perguntas seja aberta e o entrevistador tenha de estimular respostas completas.

\section{A pesquisa sobre responsabilidade social e marke- ting social}

Com o objetivo de discutir algumas evidências da situação relativa ao marketing e responsabilidade social com a situação encontrada na pesquisa, foram selecionados alguns elementos importantes que têm correlação entre os programas das empresas pesquisadas. Os dados apresentados fazem parte da pesquisa de campo realizada pelos autores. Os elementos analisados neste artigo foram extraídos de quatro empresas na região da Baixada Santista. Utilizou-se para a coleta de dados um formulário auto preenchível com escala Likert que foi aplicado pessoalmente a cada colaborador em cada empresa. Os resultados aqui expressados se referem às respostas dos questionários respondidos na presença dos pesquisadores (380) para maior validade e confiabilidade das respostas:

- dados gerais dos colaboradores, sendo de ambos os sexos e atuando em funções de operação, técnica, de supervisão e gerencial, com 380 respondentes ao todo;

- a percepção da atuação da empresa em marketing e responsabilidade social, pelos colaboradores; - atuação dos colaboradores nos programas desenvolvidos de marketing e responsabilidade social e o contexto da empresa; Procurou-se mensurar a satisfação dos colaboradores com relação ao programa de gestão da qualidade de vida no trabalho relacionando com seus valores pessoais e para os resultados esperados na empresa. Os dados foram ob- tidos na Escala Likert de 0 a 5, onde 0 significava totalmente insatisfeito e $\mathbf{5}$ totalmente satisfeito. As principais questões colocadas para cada empresa foram:

- a empresa tem um programa de marketing e responsabilidade social;

- as ações e os programas de marketing e responsabilidade social na empresa são importantes;

- os empregados valorizam as ações e os programas de marketing e responsabilidade social; - você percebe que a empresa trata o programa de marketing e responsabilidade social como uma estratégia; - o programa de marketing e responsabilidade social é uma ferramenta para o plano estratégico da empresa; - um programa de marketing e responsabilidade social poderá ser um fator que proporcione maior competitividade para empresa e promove o fortalecimento do turismo local.

\section{Análise dos resultados}

Com a Análise Fatorial Exploratória, as variáveis de cada um dos construtos foram submetidas à técnica estatística que proporcionou a comparação com a proposta previamente definida e os resultados efetivamente encontrados a partir do trabalho de campo. Com relação aos construtos Percepção do programa de marketing e responsabilidade social na empresa, As ações do programa marketing e responsabilidade social são importantes, Os empregados valorizam o programa de marketing e responsabilidade social como ferramenta para o Plano Estratégico da Empresa e a avaliação fatorial obtida manteve a expectativa previamente definida, não havendo a necessidade de qualquer ajuste.

Pelos resultados obtidos, pode-se verificar o seguinte: as médias das variáveis de interesse pessoal em marketing e responsabilidade social podem ser consideradas intermediárias, com desvios relativamente altos. As maiores médias foram verificadas nas variáveis que inquiriam sobre percepção, participação e interesse, podendo ser consideradas altas, acima de 4 . As variáveis relacionadas ao negócio em si apresentaram médias menores.

Com relação aos desvios, estes podem ser considerados como intermediários. Em geral, os desvios podem ser considerados de intermediários a altos, indicando uma dispersão relativamente elevada na avaliação dos funcionários. Homogênea foi a percepção de domínio de fator estratégico, com valores intermediários para as médias e desvios. Todas elas com valores relativamente próximos, entre 3,57 a 3,88 para médias, e desvios-padrão entre 0,89 a 1,07, em ambas as regiões. Com esses dados, conclui-se que, em geral, os funcionários consideram com boas condições para a avaliação de nível estratégico para marketing e responsabilidade social nas empresas.

Com o índice Alpha de Cronbach, as variáveis foram analisadas em sua confiabilidade para representar os construtos. O índice foi extraído para cada construto, chegando-se a valores aceitáveis, todos acima de 0,6. Com os 
resultados da estrutura fatorial encontrada, e da confiabilidade extraída, optou-se pela composição das variáveis para gerar uma medida geral de cada construto.

Tomando como regra de composição a média dos escores das entradas na planilha correspondentes para cada construto, os resultados para os valores do índice Alpha, da média, e do desvio-padrão de cada um dos construtos estão mostrados abaixo. E conforme é possível verificar na tabela 1, as médias dos construtos apresentam valores entre intermediários e altos e os desvios-padrão podem ser considerados médios. construtos associados a "obrigações legais" e "marketing como estratégia" não apresentaram influência significativa, mostrada na significância da estatística $t$ para os coeficientes padronizados.

Com os resultados obtidos e mostrados acima, é possível depreender que a ação empresarial em marketing e responsabilidade social dentro de uma empresa é fator de influência para o desempenho estratégico das pessoas e da organização. Para poder desenvolver uma maior contemplação e exploração dos dados, as medidas dos construtos foram avaliadas em relação a algumas das variáveis im-

\begin{tabular}{|l|c|c|c|}
\hline \multicolumn{1}{|c|}{ CONSTRUTO } & Alpha & Média & $\begin{array}{c}\text { Desvio } \\
\text { Padrão }\end{array}$ \\
\hline Percepção de marketing e responsabilidade social & & & 0,861 \\
\hline Ações de marketing e responsabilidade social são importantes & 0,801 & 3,43 & 0,98 \\
\hline Os empregados valorizam marketing e responsabilidade social & 0,677 & 3,65 & 0,81 \\
\hline Marketing e responsabilidade social como estratégia & 0,799 & 3,89 & 0,89 \\
\hline Marketing e responsabilidade social ferramenta estratégica & 0,854 & 3,88 & 0,92 \\
\hline Marketing e responsabilidade social como fator competitivo & 0,911 & 3,97 & 0,91 \\
\hline
\end{tabular}

Tabela 1: Resultados das médias dos construtos. Fonte: Dados da pesquisa.

Pelo resultado das médias apresentadas, é possível perceber com maior clareza o posicionamento dos colaboradores em relação aos construtos de referência ao desenvolvimento de práticas de estímulo ao desenvolvimento de marketing e responsabilidade social, que tratam fundamentalmente de atividades associadas ao universo dos negócios.

As hipóteses definidas para o estudo foram avaliadas através de Análise de Regressão Múltipla, uma vez que esta viabiliza a avaliação da influência simultânea dos fatores definidos. Assim, o construto "ação de marketing social e responsabilidade social da empresa" foi colocado na condição de dependente, ao passo que em relação à percepção de marketing e responsabilidade social, os empregados valorizam marketing e responsabilidade social (estas na mesma escala da variável dependente), e a regulamentação oficial foi inserida como independente.

Os valores do modelo de regressão estimado encontram-se na Tabela 2 . O modelo pôde ser considerado consistente $\left(R^{2}=0,381\right)$, e, como é possível verificar, apenas os portantes que foram utilizadas na pesquisa e com o uso da ANOVA (técnica estatística análise de variância), que permite testar a existência de diferenças significativas nos valores médios das diferentes alternativas de resposta para as questões avaliadas.

Posteriormente à pesquisa exploratória foi feita a pesquisa de campo junto aos munícipes, em uma amostra de 160 respondentes, com um questionário contendo questões para a seguinte indagação "Em sua opinião, que tipo de benefícios a responsabilidade social corporativa e marketing social nas empresas podem fazer para o fortalecimento do turismo na região?", os dados obtidos mostraram que a atividade turística e positiva, conforme tabela 3.

Para a indagação "Em sua opinião, a atividade turística é positiva para a cidade?", os dados obtidos mostraram que a população considera a atividade turística como positiva, conforme tabela 4, Portanto, $82,2 \%$ da população considera ótimo/bom as atividades de responsabilidade social corporativa e marketing social das empresas para o fortalecimento do turismo na região da Baixada San-

\begin{tabular}{|l|c|c|c|}
\hline \multicolumn{1}{|c|}{ CONSTRUTO } & $\begin{array}{c}\text { Coeficiente } \\
\text { padrnizado }\end{array}$ & estatística & Sig(p-valor) \\
\hline Percepção de marketing e responsabilidade social & 0,183 & 2,599 & 0,094 \\
\hline Ações de marketing e respons abilidade social são importan & 0,157 & 1,473 & 0,416 \\
\hline Os empregados valorizam marketing e responsabilidade so & 0,401 & 4,373 & 0,019 \\
\hline Marketing e responsabilidade social como estratégia & 0,277 & 1,118 & 0,673 \\
\hline Marketing e responsabilidade social ferramenta es tratégica & 0,181 & 2,266 & 0,166 \\
\hline Marketing e responsabilidade social como fator competitiv & 0,423 & 3,777 & 0 \\
\hline
\end{tabular}

Tabela 2: Resultados da regressão múltipla. Fonte: Dados da pesquisa 


\begin{tabular}{|l|c|c|}
\hline \multicolumn{1}{|c|}{ BENEFÍCIOS PARA O FORTALECIMENTO DO TURISMO } & QUANT. & \% \\
\hline Mais empregos & 74 & 46,5 \\
\hline Mais renda para a cidade & 32 & 19,8 \\
\hline progresso rápido para a cidade & 46 & 28,7 \\
\hline Nào traz benefícios para a cidade & 8 & 5,0 \\
\hline BASE & $\mathbf{1 6 0}$ & $\mathbf{1 0 0}$ \\
\hline
\end{tabular}

Tabela 3. Benefícios das atividades turísticas. Fonte: Dados da pesquisa.

\begin{tabular}{|l|c|c|}
\hline \multicolumn{1}{|c|}{ BENEFÍCIOS PARA O FORTALECIMENTO DO TURISMO } & QUANT. & \% \\
\hline Pés simo & 5 & 3 \\
\hline Ruím & 9 & 5,9 \\
\hline Regular & 12 & 7,9 \\
\hline Bom & 44 & 27,7 \\
\hline Ötimo & 87 & 54,5 \\
\hline Não soube responder & 3 & 5,0 \\
\hline BASE & $\mathbf{1 6 0}$ & $\mathbf{1 0 0}$ \\
\hline
\end{tabular}

Tabela 4. Incentivo ao Turismo. Fonte: Dados da pesquisa.

tista aliada ao incentivo do desenvolvimento turístico da região.

Aferiu-se, junto à população local, sua percepção quanto às questões relacionadas à pesquisa em termos de seu conhecimento sobre a vocação econômica (indústria, comércio e turismo da região. As empresas, para atingirem seus objetivos, além de seguirem as exigências da Legislação vigente, deverão, cada vez mais, preocupar-se com a implantação de projetos que façam parte da administração estratégica da organização. Marketing e responsabilidade social devem ser encarados como um novo elemento estratégico da empresa para proporcionar e atingir plena satisfação.

A busca da produtividade com qualidade tem sido um dos principais objetivos das empresas que pretendem sobreviver no atual cenário mundial, marcado por rápidas e profundas mudanças tecnológicas. Vive-se, portanto, numa sociedade altamente competitiva, onde a qualidade dos produtos e serviços oferecidos, aliada a uma produtividade com qualidade, constituindo-se em um diferencial estratégico. Esse diferencial consolidifica a necessidade de uma visão integrada de marketing e responsabilidade social e a gestão empresarial para melhorias contínuas.

\section{Considerações finais}

O estudo realizado proporcionou evidências de que a preocupação com marketing e responsabilidade social está cada vez mais presente como um fator estratégico dentro das organizações. Ficou patente que os programas de marketing e responsabilidade social nas empresas pesquisadas estão tomando posição de destaque e que os colaboradores e os gestores consideram que é uma ferramenta importante para o desenvolvimento econômico e do capital humano da empresa. Esse desenvolvimento, enfim, pode gerar maior motivação dos colaboradores proporcionando o incremento da produtividade, a redução de custos e, portanto, ganhos significativos de competitividade. As empresas pesquisadas, de porte médio e grande, têm uma satisfatória posição nos mercados em que atuam.

O estudo, de natureza exploratória e quantitativa, com 13 questões em escala Likert, resultou em dados estatísticos que evidenciaram que $68 \%$ dos colaboradores entrevistados têm forte percepção da importância do programa de marketing e responsabilidade social que é muito importante para as empresas (vide tabela 5).

Com relação à percepção de marketing e responsabilidade social como um diferencial estratégico e que propicia maior competitividade empresarial, $66 \%$ dos entrevistados concordam com esse fundamento (vide tabela 6).

Deste modo, a primeira limitação consiste na impossibilidade de realizar generalizações para todas as empresas e todos os setores empresariais em um escopo geográfico ampliado, bem como para outros setores de atividade. Sugere-se, assim, a reaplicação deste trabalho em outros contextos econômicos, seja envolvendo produtos ou serviços, seja para o mesmo setor analisado, em diferente região geográfica. Sugerem-se, também, pesquisas que contemplem modelos equivalentes ao proposto neste estudo para a aproximação do modelo teórico com a realidade.

Futuros estudos deverão aprofundar mais essa aná- 
lise para elucidar melhor a questão da estratégia baseada em programas de marketing e responsabilidade social, no comprometimento afetivo das pessoas dentro das empresas. Isso, para verificar, ainda, se o modo de avaliação desse comprometimento não deva sofrer uma transformação, no sentido da melhor adequação das ações e do maior envolvimento das pessoas com o negócio para seu maior desempenho e para o desempenho empresarial.

Responsabilidade social e marketing social não é somente suporte estratégico. $\mathrm{O}$ comportamento ético e a
Outra recomendação para futuros trabalhos é a mensuração da viabilidade do investimento gasto pela organização, que devem considerar ter critérios consistentes para mensurar o retorno proporcionado pelos projetos sociais, envolvendo, preferencialmente, os programas municipais de desenvolvimento turísticos de cada região.

Devem-se realizar pesquisas mais constantes para verificar se as organizações estão utilizando criteriosos instrumentos decisoriais para os objetivos a serem colimados na área social. E, finalmente, desenvolver estudos para

\begin{tabular}{|c|c|}
\hline PERCEPÇÃO DA IMPORTÂNCIA DO PROGRAMA DE & $\%$ \\
MARKETING E RESPONSABILIDADE SOCIAL & \\
\hline Forte percpção da influência de marketing e respons abilidade social & 68,0 \\
\hline Moderada percpção da influência de marketing e responsabilidade so & 27,3 \\
\hline Fraca percpção da influência de marketing e responsabilidade social & 4,0 \\
\hline Sem percpção da influência de marketing e responsabilidade social & 0,7 \\
\hline
\end{tabular}

Tabela 5. Percepção de Marketing e Responsabilidade Social como diferencial estratégico. Fonte. Dados da pesquisa.

\begin{tabular}{|l|c|}
\multicolumn{1}{|c|}{ PERCEPÇAO MARKETING E RESPONSABILIDADE SOCIAL } & $\%$ \\
\hline COMO DIFERENCIAL ESTRATÉGICO & \\
\hline Forte percpção da influência de marketing e responsabilidade social & 66,0 \\
\hline Moderada percpção da influência de marketing e respons abilidade social & 26,5 \\
\hline Fraca percpção da influência de marketing e respons abilidade social & 6,2 \\
\hline Sem percpção da influência de marketing e respons abilidade social & 1,3 \\
\hline $\begin{array}{l}\text { Tabela 6. Percepção de Marketing e Responsabilidade Social como diferencial estratégico. Fonte. Dados } \\
\text { da pesquisa. }\end{array}$
\end{tabular}

transparência no trato de todas as questões que envolvem a empresa e que influenciam direta ou indiretamente a comunidade próxima, e a sociedade de uma forma geral, também contribuem para a formação da empresa cidadã constituindo em imprescindível filosofia de gestão. Podem apoiar, também, o fortalecimento do turismo na região. As campanhas de marketing social podem proporcionar credibilidade ao nome da empresa junto aos mercados e consumidores finais, quando a base da campanha estiver fundamentada em consistentes programas de responsabilidade social corporativa. São polarizadores de pontos positivos que surgem após sua implementação e podem fortalecer os anseios turísticos da região estudada.

Este trabalho procurou colaborar para o avanço do conhecimento em marketing e responsabilidade social, constituindo-se em mais um passo no sentido de trazer contribuições para futuras investigações sobre o tema. Por esta razão, espera-se ter estimulado novas pesquisas e debates que envolvem marketing e responsabilidade social e fortalecimento das ações turísticas, extremamente em evidência para o desenvolvimento sócio-econômico em face da crescente complexidade dos mercados.

Recomendam-se, futuros trabalhos, no sentido de que a decisão de uma empresa de participar do desenvolvimento de algum projeto social não seja somente do principal gestor da organização e sim, compartilhada por todos os membros da organização. a concepção de modelos de gestão para que as empresas possam analisar os resultados a serem obtidos com o marketing social e responsabilidade social corporativa.

\section{Referências}

Almeida, F.

2007. Os Desafios da sustentabilidade. São Paulo. Campus.

Andrade, R.O. B., Tachizawa, T.; Carvalho, A B.

2002, Gestão ambiental: enfoque estratégico aplicado ao desenvolvimento sustentável. São Paulo. Pearson Education.

Angelides,J.P; Ibrahin,N.A.

1993. "Social demand and corporete supply: a corporate social responsibility model". Review Business, 15: 7-10. Aragão, S.D.

2000. "A responsabilidade social das empresas considerada nas decisões de concessão de crédito por bancos de desenvolvimento no Estado de Santa Catarina”. Dissertação (Mestrado em Administração), Universidade Federal de Santa Catarina. Florianópolis.

Bronn,P.; Vrioni,A.

2000. Measuring skepticism to cause related marketing: pre-liminary Norwegian results. Handelshoyskolen BI, Norwegian, pp.3. 
Carroll, A.B.

1991. "The pyramid of corporate social responsibility: toward the moral management of organizational stakeholders", Business Horizons, 34(4): 39-48.

Carroll, A. B.

1999. "Corporate social responsibility: evolution of a definitional construct." Business and Society, 38(3): 268295.

Carroll, A. B. e Schwartz, M.

2003. "Corporate Social Responsibility: A Three-Domain Approach.” Business Ethics Quarterly, 13(4): 503-530.

Duarte,G.D; Dias,J.M.M.

1986. Responsabilidade social: a empresa hoje. Rio de Janeiro: LTC. EMBRATUR. Instituto Brasileiro de Turismo.

2009. "Estatísticas sobre o Turismo no Brasil". Disponível em http://www.embratur.gov.br. Acesso em 20 de abril de 2009 .

Enderle,E.T.

1998. "Balanced concept $\mathrm{f}$ the firm and measurement of its long-term planning e performance”. Journal of business Ethics. v.17. pp. 1129-1144.

ETHOS - Instituto Ethos de Responsabilidade Social.

2007. "Matriz de Evidências de Sustentabilidade, Banco de Práticas e Ferramentas de gestão: Indicadores Ethos", Guia de Elaboração de Balanço Social. Disponível em: www.ethos.org.br. Acesso em: 01 dez. 2007.

Froes,C.M.; Neto,F.P.

1999. Responsabilidade social \& cidadania empresarial: a administração do terceiro setor. Rio de Janeiro: Qualitymark.

Gaioto,F.R.

2001. "Da responsabilidade social à ética empresarial”. Florianópolis: UFSC, p.62, Ensaio.

Garcia,I; Gibaja,J.J.;Mujika,A.

2001. "Marketing social corporativo - la res-puesta a una demanda social". Estudios Empresariales, n.105, pp. 26-32.

Glaser, B.; Strauss, A.

1967. The Discovery of Grounded Theory, Chicago: Aldine, 1967.

Glaser, B.; Holton, J.

2004. "Remodeling Grounded Theory". The Grounded Theory Review, v. 4, n. 1.

Gonçalves, L.E.

1980. Balanço Social da empresa na América Latina. São Paulo: Pioneira.

Henderson, $\mathrm{H}$.

2001. Transcendendo a economia. Tradução de Merle Scoss. $10^{\mathrm{a}}$ ed. São Paulo: Editora Cultrix, 274 p. Título original: Paradigms in Progress, 2001.

Izquierdo,G.B.

2000. El valor de compartir beneficios - las ONGD y el marketing con causa: retos y oportunidades. Bilbao: Universidad de Deusto.

Kotler, P.

2007. Marketing. São Paulo, Atlas

Kotler, P.

2008. Marketing Social, São Paulo, Atlas

Kotler,P.; Zaltman,G.

1971."Social marketing an approach to planned social change". Journal of Marketing, 35: 3-12.

Kozel Junior,J.
1997. O Top do Marketing Brasileiro. São Paulo: Scipione, pp. 214.

Leisinger,K.M

2001. Etica empresarial: responsabilidade global e gerenciamento moderno. Petrópolis, Vozes.

Llena,F.

2005. La responsabilidad social de la empresa, 5campus. com, Medio Ambiente. www.5campus.com/leccion/medio em maio de 2005.

McCarthy, J.

2000. "Approximate objects and approximate theories". In Cohn, A. G., Giunchiglia, F.;Selman,

B., Principles of Knowledge Representation and Reasoning, Proceedings of the Seventh International conference, Morgan-Kaufman. Pp. 519-526

Masso,G.R.

1998. El beneficio de compartir valores - marketing social corporativo, una nueva estrategia para diferenciar las marcas. Bilbao: Deusto.

Mattar,F.N.

1995. Pesquisa de Marketing. Atlas, São Paulo.

Richers, R.

2001. Marketing, Uma visão brasileira. São Paulo, Nobel.

SEADE. Índice Paulista de Responsabilidade Social. São Paulo.

2001. Disponível em: http://www.seade.gov.br. Acesso em: .31.03.2009.

Scour,H.R.

1998. Poder, cultura e ética nas organizações. Rio de Janeiro. Campos.

Strauss, A.; Corbin, J.

1997. Grounded Theory in Practice, Sage Publications, London.

Tachizawa,T

2010. Gestão Ambiental e Responsabilidade Social Corporativa. $6^{\text {a }}$. edição. São Paulo. Atlas.

Valor, M.

2001. "Responsabilidad social de la empresa, marketing de relaciones y política de recursos humanos: el gasto social de la empresa". Papeles de Ética, Economía y Dirección, n.6.

Vaz, G. N.

1995. Marketing institucional: um mercado de idéias. São Paulo: Pioneira.

Zenone, L. C.

2006. Marketing Social. São Paulo, Thomson, pp.207.

Waddock. S. A; Graves, S. B.

1997. "The corporate social performance: financial performance link". Strategic Management Journal, 18(4): 303-319.

Wartick, S. E Cochran, P.

1985. "The evolution of the corporate social performance model». Academy of Management Review, 10: 758-769.

Wgeatley, M J.

1992. Liderança e a nova ciência. São Paulo, Cultrix.

Wood, D. J.

1991. "Toward improving corporate social performancebuilding "the good society»", Business Horizons, 34(4): 66-73.

Recibido:

$11 / 07 / 2009$

Reenviado:

$20 / 12 / 2010$

Aceptado:

$30 / 12 / 2010$

Sometido a evaluación por pares anónimos 